\title{
MODAL SOSIAL PETANI MISKIN DALAM STRATEGI BERTAHAN HIDUP DI KABUPATEN MINAHASA
}

\section{SOCIAL CAPITAL OF POOR FARMERS IN THE SURVIVAL STRATEGY IN MINAHASA DISTRICT}

\author{
Charles Reijnaldo Ngangi ${ }_{-}^{(1)}$, Lyndon Reindhart Jacob Pangemanan ${ }^{(1)}$, Tommy Ferdy Lolowang_(1) \\ 1) Dosen Program Studi Agribisnis, Fakultas Pertanian, Universitas Sam Ratulangi, Manado \\ *Penulis untuk korespondensi: charlesr.ngangi@ gmail.com
}

Naskah diterima melalui Website Jurnal Ilmiah agrisosioekonomi@unsrat.ac.id

Rabu, 27 Januari 2021

Disetujui diterbitkan

Jumat, 28 Mei 2021

\begin{abstract}
This study aims to study social capital in the survival strategies of poor farmers. The research was conducted for 6 months, from April to October 2020, with the research location in Minahasa Regency. This research was designed descriptively, with a survey method. Sampling was selected purposively on farmers in Minahasa district with 100 farmers as respondents. The data collected in this study are primary and secondary data. Primary data were collected directly through in-depth interviews with farmers. The results showed that the stronger the farmer's social capital, the better his survival strategy. On the other hand, the weaker the social capital, the poor farmer's survival strategy was getting worse.
\end{abstract}

Keywords: social capital; survival strategies; poverty; farmers

Penelitian ini bertujuan untuk mempelajari tentang modal sosial dalam strategi bertahan hidup petani miskin. Penelitian dilaksanakan selama 6 bulan, mulai bulan April sampai dengan Oktober 2020, dengan lokasi penelitian di Kabupaten Minahasa. Penelitian ini dirancang secara deskriptif, dengan metode survei. Pengambilan sampel dilakukan secara sengaja (purposive sampling) pada Petani di Kabupaten Minahasa dengan jumlah responden 100 petani. Data yang dikumpulkan dalam penelitian ini adalah data primer dan sekunder. Data primer dikumpulkan secara langsung melalui wawancara mendalam dengan petani. Hasil penelitian menunjukan bahwa semakin kuat modal sosial petani maka semakin baik strategi bertahan hidupnya sebaliknya semakin lemah modal sosial maka strategi bertahan hidup petani miskin menjadi semakin kurang baik.

Kata kunci : Modal Sosial; Strategi Bertahan Hidup; Kemiskinan; Petani 


\section{PENDAHULUAN}

\section{Latar Belakang}

Sektor pertanian sampai saat ini masih tetap memegang peran penting dan strategis dalam perekonomian nasional. Peran strategis tersebut tidak hanya ditunjukkan dengan kontribusi sektor pertanian terhadap produk domestik bruto nasional tetapi juga sebagai penyedia lapangan kerja (Alfurkon, 2014). Pusat data dan sistem informasi pertanian mencatat Tenaga kerja pertanian merupakan tenaga kerja terbesar dengan jumlah mencapai 36,91 juta orang pada Februari tahun 2018. Jumlah ini merupakan $28,23 \%$ dari jumlah tenaga kerja Indonesia seluruhnya.

Profesi sebagai petani biasanya digunakan sebagai perlindungan dari status pengangguran, sehingga banyak petani yang dikategorikan sebagai petani miskin. Sugihardjo (2012) mengemukakan bahwa dengan kebutuhan hidup yang besar memacu petani untuk berperilaku sebagai petani survival demi memenuhi kebutuhannya, masalah yang dihadapi petani adalah bagaimana menghasilkan beras yang cukup untuk makan sekeluarga dan untuk membeli barang kebutuhan lainnya. Petani lebih suka meminimumkan terjadinya bencana dari pada memaksimumkan penghasilan rataratanya, hal ini yang disebut risk averse (menolak resiko).

Petani berperilaku sebagai petani survival agar segala tuntutan kebutuhan untuk kelangsungan hidup keluarganya dapat terpenuhi. Petani mempertahankan hidup dengan segenap kemampuannya dan kemudian memutuskan isolasi yang menghambat komunikasi survivor dengan masyarakat umum. Petani yang sangat identik dengan petani survival adalah buruh tani. Bannet dalam Araini (2006) mengemukakan teori household survivallife (kelangsungan hidup rumah tangga) yaitu polapola yang dibentuk oleh berbagai usaha yang digunakan oleh manusia untuk memenuhi syarat minimal yang dibutuhkannya dan untuk memecahkan masalah yang mereka hadapi.

Pendekatan kemiskinan yang dilakukan saat ini adalah pendekatan modal sosial, modal sosial dapat membantu dalam pengentasan kemiskinan. Modal sosial dapat menjadi modal stimulan yang dimiliki oleh petani miskin untuk terbukanya peluang dan potensi modal lainnya. Konsep modal sosial, yang awalnya dipahami sebagai suatu bentuk dimana masyarakat menaruh kepercayaan terhadap komunitas dan individu sebagai bagian di dalamnya, mereka membuat kesepakatan bersama sebagai suatu nilai dalam komunitasnya. Modal sosial diartikan pula sebagai stok kepercayaan sosial, norma dan jaringan dimana masyarakat dapat menggambarkan penyelesaian problem umum (Ngangi, 2016). Modal sosial sebagai penentu dan dasar kehidupan masyarakat yang teratur dan sejahtera. Modal sosial ini merupakan potensi yang dapat menjadi energi dalam menjembatani dan memperkuat bahkan menstimuli potensi modal lainnya dalam suatu komunitas.

Berdasarkan data Badan Statistik Kabupaten Minahasa, luas lahan pertanian pada tahun 2018 untuk lahan persawahan $7.574 \mathrm{Ha}$, luas kebun 29.064 Ha, dan luas ladang 16.294 Ha. Jumlah Penduduk Kabupaten Minahasa yang bekerja di sektor pertanian sebesar 37.187 atau $23.07 \%$ dari total jumlah penduduk yang bekerja. Dari data tersebut terlihat bahwa bertani merupakan pekerjaan yang banyak dilakukan oleh masyarakatnya. Jumlah penduduk miskin di Kabupaten Minahasa terbanyak di Sulawesi Utara mencapai 24.490 jiwa (BPS, 2019).

\section{Modal Sosial}

Modal Sosial adalah sumberdaya yang dapat dipandang sebagai investasi untuk mendapatkan sumberdaya baru. Seperti diketahui sumberdaya (resources) adalah sesuatu yang dapat dipergunakan untuk dikonsumsi, disimpan, dan diinvestasikan. Sumberdaya yang digunakan untuk investasi disebut sebagai modal, antara lain modal sosial. Dimensi Modal Sosial cukup luas dan kompleks, Modal Sosial berbeda dengan Modal Manusia (human capital). Pada modal manusia segala sesuatunya lebih merujuk ke dimensi individual, yaitu daya dan keahlian yang dimiliki oleh seorang individu. Pada Modal Sosial, lebih menekankan pada potensi kelompok dan pola-pola hubungan antar individu dalam suatu kelompok dan antar 
kelompok. Modal sosial lebih memperhatikan jaringan sosial, norma, dan kepercayaan antar sesama yang lahir dari anggota kelompok dan menjadi norma kelompok (Hasbullah, 2006).

\section{Kemiskinan}

Kemiskinan terkait dengan masalah kekurangan pangan dan gizi, keterbelakangan pendidikan, kriminalisme, pengangguran, prostitusi. dan masalah-masalah lain yang bersumber dari rendahnya tingkat pendapatan perkapita penduduk. Kemiskinan merupakan masalah yang amat kompleks dan tidak sederhana penanganannya. Menurut Mulyono (2006) kemiskinan berarti ketiadaan kemampuan dalam seluruh dimensinya. Kemiskinan juga berarti marginalisasi, penggusuran orang-orang oleh kemajuan pembangunan. Polarisasi, kesenjangan yang makin lebar. Menanggulangi kemiskinan bukanlah tugas yang ringan, karena berhubungan erat dengan berbagai masalah dari segi kehidupan. Misalnya, dengan keadaan daerah, kegiatan penduduk, tingkat pendidikan, dan kesehatan (Ngangi, 2013; 2014).

\section{Strategi Bertahan Hidup}

Strategi bertahan hidup merupakan suatu pemahaman bagaimana rumah tangga mengelola dan memanfaatkan aset sumber daya dan modal yang dimiliki melalui kegiatan tertentu yang dipilih. Suharto (2009) mendefinisikan strategi bertahan sebagai kemampuan seseorang dalam menerapkan seperangkat cara untuk mengatasi berbagai permasalahan yang melingkupi kehidupannya, strategi penanganan masalah ini pada dasarnya merupakan kemampuan segenap anggota keluarga dalam mengelola aset yang dimilikinya. Strategi bertahan hidup sebagai rangkaian tindakan yang dipilih secara standar oleh individu dan rumah tangga yang miskin secara sosial ekonomi. Rumah tangga yang menerapkan strategi survival pada umumnya berada pada garis kemiskinan yang dicirikan oleh kepemilikan lahan atau aset sumber daya yang terbatas.

\section{Rumusan Masalah}

Berdasarkan uraian latar belakang di atas, maka permasalahannya adalah Bagaimana modal sosial petani miskin dalam strategi bertahan hidup di Kabupaten Minahasa?

\section{Tujuan Penelitian}

Tujuan penelitian ini untuk mempelajari tentang modal sosial dalam strategi bertahan hidup. Diharapkan dari penelitian yang dilaksanakan ini, akan diketahui tentang modal sosial petani miskin dan strategi bertahan hidup di Kabupaten Minahasa.

\section{Manfaat Penelitian \\ Manfaat penelitian ini adalah sebagai} berikut:

1. Hasil dari penelitian ini diharapkan dapat memberi bahan masukan bagi para pengambil kebijakan dalam menentukan bentuk dan strategi bertahan hidup serta modal sosial petani miskin

2. Dalam bidang sosial khususnya modal sosial, sangat diperlukan penelitian yang mengacu pada peningkatan pembangunan karakter masyarakat, selain berkomplementasi dengan bidang teknis agar inovasi yang dihasilkan dapat diterapkan dengan baik dalam kehidupan masyarakat.

\section{METODE PENELITIAN}

\section{Waktu dan Tempat Penelitian}

Penelitian ini dilaksanakan selama 6 bulan, mulai bulan April sampai dengan Oktober 2020, dengan lokasi penelitian di Kabupaten Minahasa.

\section{Metode Penelitian}

Penelitian ini dirancang secara deskriptif, dengan metode survey. Pengambilan sampel (responden) dilakukan secara purposive terhadap Petani di Kabupaten Minahasa. Jumlah respon 100 petani. Data yang dikumpulkan dalam penelitian ini meliputi data primer dan sekunder dikumpulkan secara langsung dengan teknik survey melalui wawancara mendalam (in dept interview) dengan petani. Data ini meliputi umur, tingkat pendidikan, karakteristik perumahan, status kepemilikan rumah, pendapatan dan pengeluaran petani. Data sekunder berupa kondisi geografis, keadaan sosial ekonomi dan budaya masyarakat. Dalam pengumpulan data metode yang digunakan adalah metode survey melalui wawancara langsung dengan berpedoman pada daftar pertanyaan (kuesioner) yang telah dirancang dan dipersiapkan. 


\section{Konsep Pengukuran Variabel}

Adapun yang terjadi konsep pengukuran variable dalam penelitian ini adalah sebagai berikut:

1. Modal sosial petani yang meliputi kepercayaan, norma dan jaringan.

1) Kepercayaan

a. Kejujuran anggota dalam melaksanakan tugas kelompok

b.Kemurahan hati setiap anggota untuk membantu anggota lain yang membutuhkan

c. Toleransi dengan anggota lain yang berhalangan

d.Pendapat anggota tentang ketua kelompok

e. Kewajaran dari kas kelompok

2) Norma

a. Norma yang mengikat anggota untuk tinggal dalam kelompok

b. Kepatuhan anggota terhadap aturan yang ada

c. Imbalan yang di dapatkan anggota dalam kelompok

d. Sanksi yang di dapatkan anggota dalam kelompok

3) Jaringan

a. Hubungan kerjasama antar kelompok dengan kelompok/instansi lain

b.Partisipasi kelompok terhadap kegiatan - kegiatan di luar kelompok

c. Hubungan timbal balik kelompok dengan kelompok/instansi lain

d. Keadilan dalam hubungan timbal balik dengan kelompok lain

2. Karakteristik Petani: Umur, tingkat pendidikan, pendapatan dan pengeluaran petani.

3. Karakteristik tempat tinggal dan status kepemilikan rumah,

4. Strategi bertahan hidup

a. Relasi atau jaringan Sosial

b. Alternatif subsistensi

c. Pengontrolan konsumsi dan pengeluaran

\section{Metode Analisis Data}

1. Karakteristik Petani: Untuk mengetahui kondisi masyarakat dan keadaan sosial budaya yang ada serta faktor- faktor yang karakteristiknya berdasarkan pengamatan di lapangan dianalisis secara deskriptif.
2. Strategi bertahan hidup:

1) Relasi atau jaringan Sosial:

a. Menitipkan anak ke sanak saudara atau kerabat

b. Strategi pinjaman uang

c. Mengikuti arisan

d.Intensitas keluarga petani dalam mengikuti ibadah

e. Mendapat bantuan pemerintah

2) Alternatif subsistensi

a. Berjualan kecil-kecilan

b. Menggunakan barang bekas untuk kebutuhan rumah tangga

c. Bekerja serabutan

d.Melakukan migrasi untuk mencari pekerjaan

3) Pengontrolan konsumsi dan pengeluaran:

a. Mengurangi pola makan, dari 3 kali sehari menjadi 2 kali sehari

b. Membeli barang-barang murah

c. Pembelian pakaian dalam setahun

d. Mengurangi pengeluaran untuk kesehatan

e. Mengurangi pengeluaran untuk biaya pendidikan

Strategi Bertahan Hidup untuk skor Indikator pada masing-masing Variabel sbb: Setiap jawaban Ya diberi skor 2 dan setiap jawaban Tidak diberi skor 1 .

1) Variabel Relasi dan Jaringan Sosial, Skor tertinggi $2 \times 100$ responden $=200$ dikalikan dengan 5 indikator $=5$ X $200=1000$. Sedangkan skor terendah 1 X $100=100$ dikalikan 5 indikator 5 X $100=500$.

2) Variabel Alternatif Subsistens, Skor tertinggi $2 X$ 100 responden $=200$ dikalikan dengan 4 indikator $=4 \times 200=800$. Sedangkan skor terendah 1 X 100 responden $=100$ dikalikan 4 indikator 4 X $100=400$.

3) Variabel Pengontrolan Kontribusi dan Pengeluaran, Skor tertimggi $2 \times 100$ responden $=$ 200 dikalikan dengan 5 indikator $=5 \times 200=$ 1000. Sedangkan skor terendah $1 \quad X \quad 100$ responden $=100$ dikalikan 5 indikator $5 \mathrm{X} 100=$ 500 . 
Nilai skala tertinggi $=$ Relasi atau Jaringan Sosial + Alternatif Subsistens + Pengontrolan Konstribusi dan Pengeluaran = $1000+800+1000=2800$.

Nilai skala terendah $=$ Relasi atau Jaringan Sosial + Alternatif Subsistens + Pengontrolan Konstribusi dan Pengeluaran $=500+400+500$ $=1400$.

$0|\quad 21400 \quad| \quad 280 \quad \mid \quad 2800 \quad$ |

Skala $0-1400=$ Strategi Bertahan Hidup Kurang Skala $1401-2100=$ Strategi Bertahan Hidup Sedang Skala $2101-2800=$ Strategi Bertahan Hidup Baik.

\section{Modal Sosial}

\section{Skala Tertinggi}

\section{1) Kepercayaan}

$\begin{array}{lll}\text { a. Kejujuran } & : 3(\text { Skor Tertinggi }) \times 100(\text { Responden }) & =300 \\ \text { b. Kemurahan Hati } & : 3 \text { (Skor Tertinggi }) \times 100(\text { Responden }) & =300 \\ \text { c. Toleransi } & : 3 \text { (Skor Tertinggi) } \times 100(\text { Responden }) & =300 \\ \text { d. Egaliter } & : 3(\text { Skor Tertinggi }) \times 100(\text { Responden }) & =300 \\ \text { e. Kewajaran } & : 3(\text { Skor Tertinggi }) \times 100(\text { Responden }) & =300 \\ \text { Jumlah } & =\mathbf{1 5 0 0}\end{array}$

2) Norma :

a. Norma

b. Aturan

c. Sanksi

d. Imbalan

$: 3$ (Skor Tertinggi) $\times 100($ Responden) $=300$

$: 3$ (Skor Tertinggi) $\times 100$ (Responden) $=300$

$: 3$ (Skor Tertinggi) $\times 100$ (Responden) $=300$

$: 3$ (Skor Tertinggi) $x 100$ (Responden) $=300$

Jumlah $\quad=1200$

3) Jaringan :

a. Kerjasama $: 3$ (Skor Tertinggi) $\times 100$ (Responden) $=300$

b. Partisipasi : 3 (Skor Tertinggi) $\times 100$ (Responden) $=300$

c. Timbal Balik : 3 (Skor Tertinggi) $\times 100$ (Responden) $=300$

d. Keadilan : 3 (Skor Tertinggi) $\times 100$ (Responden) $=300$

Skala Terendah

Jumlah $\quad=1200$

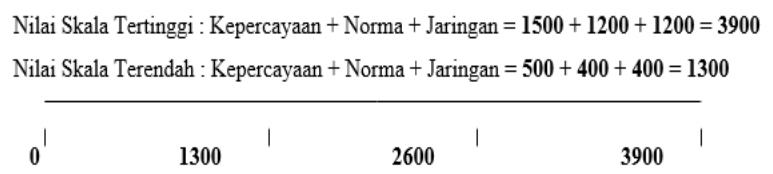

Skala $0-1300=$ Modal sosial lemah

Skala $1301-2600=$ Modal sosial cukup

Skala $2601-3900=$ Modal sosial kuat

\section{HASIL DAN PEMBAHASAN}

\section{Deskripsi Wilayah}

Kabupaten Minhasa adalah sebuah Kabupaten di Provinsi Sulawesi Utara. Terletak antara 00 01'00" sampai 010 29'00 Lintang Utara dan 111o sampai 124o 05'00" Bujur Timur. Luas wilayah Kabupaten Minasa, adalah berupa daratan seluas 1.141,64 km2. Kabupaten Minahasa memiliki ketinggian rata-rata \pm 591 meter diatas permukaan laut. . Berdasarkan ketinggian dari permukaan laut, dataran di Kabupaten Minahasa terdiri dari: (1) 0m$100 \mathrm{~m}=8 \%$; (2) $101 \mathrm{~m}-500 \mathrm{~m}=16 \%$; (3) $501 \mathrm{~m}$ $1000 \mathrm{~m}=76 \%$.

Berdasarkan posisi geografisnya, kabupaten Minahasa memiliki batas-batas:

a) Sebelah Utara berbatasan : Laut Sulawesi, Kota Manado dan Kota Tomohon

b) Sebelah Selatan berbatasan : Kecamatan Sonder (Kabupaten Minahasa)

c) Sebelah Barat berbatasan : Kebupaten Minahasa Selatan dan Kota Tomohon

d) Sebelah Timur : : Laut Maluku, Kabupaten Minahasa Utara dan Kota Tomohon

\section{Karakteristik Responden}

Umumnya faktor pendidikan dijadikan sebagai indikator untuk menerima tanggung jawab suatu pekerjaan. Seseorang dengan pendidikan tertentu dalam menerima tanggung jawab suatu pekerjaan akan memilih-milih mana pekerjaan ringan atau menyenangkan yang sesuai dengan tingkat pendidikannya. Biasanya orang yang berpendidikan tinggi akan memilih pekerjaan yang tidak terlalu membutuhkan pekerjaan secara fisik. Pada tabel 1 diperoleh tingkat pendidikan responden.

\begin{tabular}{lc} 
Tabel 1. Tingkat pendidikan responden & \\
\hline Pendidikan (tahun) & Responden (orang) \\
\hline Tidak tamat SD (<6 thn) & 8 \\
Tamat SD-Tdk tamat SMP ( $6-9$ thn $)$ & 21 \\
Tamat SMP-tdk tamat SMU (9-12 thn) & 33 \\
Tamat SMU ke atas ( > 12 thn $)$ & 38 \\
\hline Jumlah & $\mathbf{1 0 0}$ \\
\hline
\end{tabular}


Tabel 1 menunjukkan umumnya responden pada penelitian ini berpendidikan menengah ke atas yakni sekitar 33 orang berpendidikan tamat SMP sampai dengan tamat SMA ke atas 28 orang tamat SMA ke atas.

Kemampuan seseorang untuk melakukan sesuatu perkerjaan atau usaha sangat berhubungan dengan usianya. Kemampuan bekerja seseorang tersebut akan meningkat searah dengan bertambahnya usia, tetapi pada tahap tertentu dengan makin bertambahnya usia maka kemampuan tersebut akan menurun. Pada tabel 2 di bawah ini, terlihat kelompok usia dari responden pada penelitian ini.

Tabel 2. Kelompok usia responden

\begin{tabular}{cc}
\hline Usia (tahun) & Responden (orang) \\
\hline $20-30$ & 11 \\
$31-40$ & 23 \\
$41-50$ & 29 \\
$>51$ & 36 \\
\hline Jumlah & $\mathbf{1 0 0}$ \\
\hline
\end{tabular}

Berdasarkan hasil penelitian menurut usia responden, maka diperoleh usia responden yakni 63 orang berusia sangat produktif, terdiri dari 11 orang berusia $20-30$ tahun, 23 orang berusia 3140 tahun dan 29 orang yang berusia 41-50 tahun.

Tabel 3. Pendapatan Responden

\begin{tabular}{cc}
\hline Pendapatan (rupiah) & Responden (orang) \\
\hline $500,000-1.000 .000$ & 13 \\
$1.100,000-2.500 .000$ & 45 \\
$2.500 .000-5.000 .000$ & 34 \\
$>5.000 .000$ & 8 \\
\hline Jumlah & $\mathbf{1 0 0}$ \\
\hline
\end{tabular}

Responden pada penelitian ini yakni sebanyak 13 orang mempunyai pendapatan antara $\mathrm{Rp}$ 500,000 sampai dengan $\mathrm{Rp} 1.000 .000,45$ orang berpendapatan $\mathrm{Rp} \quad 1.100 .000$ samai dengan $\mathrm{Rp}$ 2.500.000, 34 orang berpendapatan $\mathrm{Rp} 2.500 .000$ sampai dengan Rp 5.000.000 serta 8 orang dengan pendepatan lebih dari Rp 5.000.000.

\begin{tabular}{cc} 
Tabel 4. Pengeluaran Responden & \\
\hline Pengeluaran (rupiah) & Responden (orang) \\
\hline $250.000-1.000 .000$ & 13 \\
$1.100,000-2.000 .000$ & 46 \\
$2.100 .000-3.000 .000$ & 30 \\
$>3.000 .000$ & 11 \\
\hline Jumlah & $\mathbf{1 0 0}$ \\
\hline
\end{tabular}

Responden pada penelitian ini yakni sebanyak 13 orang memiliki pengeluaran Rp 250,000 sampai dengan Rp1.000.000, 46 orang berpengeluaran $\mathrm{Rp} 1.100 .000$ sampai dengan $\mathrm{Rp}$ 2.000.000, 30 orang berpengeluaran $R p 2.100 .000$ sampai dengan Rp3.000.000 serta 11 orang dengan pengeluaran lebih dari Rp 3.000.000.
Tabel 5. Lama Tinggal

\begin{tabular}{cc}
\hline Lama Tinggal (tahun) & Responden (orang) \\
\hline$<5$ & 8 \\
$5-10$ & 17 \\
$10-25$ & 26 \\
$>25$ & 49 \\
\hline Jumlah & $\mathbf{1 0 0}$ \\
\hline
\end{tabular}

Responden pada penelitian ini, umumnya adalah penduduk tetap karena 75 orang sudah lebih dari 10 tahun menetap dan hanya 25 orang yang lama tinggal di bawah 10 tahun.

\section{Strategi Bertahan Hidup}

Strategi bertahan hidup sebagai rangkaian tindakan yang dipilih secara standar oleh individu dan rumah tangga yang miskin secara sosial ekonomi.

Tabel 6. Relasi atau jaringan Sosial

\begin{tabular}{lc}
\hline \multicolumn{1}{c}{ Indikator } & Skor \\
\hline Menitipkan anak ke sanak saudara atau kerabat & 170 \\
Strategi pinjam uang & 180 \\
Mengikuti arisan & 120 \\
Intensitas keluarga petani dalam mengikuti ibadah & 170 \\
Mendapat bantuan pemerintah & 110 \\
\hline \multicolumn{2}{c}{ Jumlah } \\
\hline
\end{tabular}

Tabel 6 menunjukkan Petani sering menitipkan anak kepada saudara ataupun kerabat. Strategi pinjam uang menjadi alternatif bagi petani dalam memenuhi kebutuhan kehidupan sehari-hari dan untuk modal bertani. Masih sedikit petani masih yang mengikuti arisan serta mendapatkan bantuan pemerintah. Dalam melaksanakan usaha sebagai petani, tidak membuat petani meninggalkan ibadah dalam melaksanakan tugasnya. Total skor Relasi atau jaringan sosial berjumlah 750 .

Tabel 7. Alternatif subsistensi

\begin{tabular}{lc}
\hline \multicolumn{1}{c}{ Indikator } & Skor \\
\hline Berjualan kecil-kecilan & 180 \\
Menggunakan barang bekas untuk kebutuhan & 160 \\
rumah tangga & \\
Bekerja serabutan & 160 \\
Melakukan migrasi untuk mencari pekerjaan & 110 \\
\hline \multicolumn{2}{c}{ Jumlah } \\
\hline
\end{tabular}

Tabel 7 berjualan kecil-kecilan menjadi alternatif subsistensi yang kuat bagi petani. Petani menjadikan penggunaan barang bekas sebagai alternatif untuk kebutuhan rumah tangga. Jika terdapat kendala dalam modal dalam bertani dan pemenuhan kebutuhan sehari-hari, petani menjalankan pekerjaan serabutan, bahkan ada anggota keluarga yang melakukan migrasi untuk mencari pekerjaan. total skor alternatif subsistensi adalah 610 . 
Tabel 8. Pengontrolan konsumsi dan pengeluaran

\begin{tabular}{lc}
\multicolumn{1}{c}{ Indikator } & Skor \\
\hline Mengurangi pola makan, dari 3 kali sehari menjadi & 170 \\
2 kali sehari & \\
Membeli barang-barang murah & 200 \\
Pembelian pakaian dalam setahun & 130 \\
Mengurangi pengeluaran untuk kesehatan & 160 \\
Mengurangi pengeluaran untuk biaya pendidikan & 160 \\
\hline \multicolumn{2}{c}{ Jumlah } \\
\hline
\end{tabular}

Tabel 8 menggambarkan petani mengurai pola makan dari 3 kali makan sehari menjadi 2 kali makan sehari. Membeli barang mrah menjadi pilihan petani dalam memenuhi kebutuhan. Untuk pembelian pakaian, biasanya dilakukan pada hari raya besar keagamaan. Pendidikan belum menjadi prioritas utama bagi petani untuk menyekolahkan anak. Pada umunya hanya sampai jenjang SMA. Sedangkan biaya kesehatan masih kurang. Total skor untuk Pengontrolan konsumsi dan pengeluaran adalah 820 .

Dari data di atas, total skor strategi bertahan hidup petani miskin di kabupaten Muninahasa adalah 2180. Hal ini mengindikasikan bahwa strategi bertahan hidup petani miskin di daerah ini tergolong kuat.

Strategi bertahan hidup merupakan kemampuan seseorang dalam menerapkan seperangkat cara untuk mengatasi berbagai permasalahan yang melingkupi kehidupannya, Berdasarkan tabel 16, menunjukan bahwa mulai dari strategi relasi atau jaringan sosial, alternatif subsistensi, sampai dengan pengontrolan konsumsi dan pengeluaran maka umumnya atau di atas di 60 persen petani mampu untuk bertahan hidup. Hal ini diakibatkan bahwa para petani sudah turun temurun melakukan aktivitas usaha tani dan cara untuk bertahan hidup.

\begin{tabular}{|c|c|c|c|}
\hline Strategi & Baik & Sedang & Kurang \\
\hline \multicolumn{4}{|l|}{ 1) Relasi atau jaringan Sosial: } \\
\hline $\begin{array}{l}\text { Menitipkan anak ke sanak saudara } \\
\text { atau kerabat }\end{array}$ & 21 & 62 & 17 \\
\hline Strategi pinjaman uang & 73 & 17 & 10 \\
\hline Mengikuti arisan & 13 & 25 & 62 \\
\hline $\begin{array}{l}\text { Intensitas keluarga petani dalam } \\
\text { mengikuti ibadah }\end{array}$ & 78 & 17 & 5 \\
\hline Mendapat bantuan pemerintah & 5 & 23 & 72 \\
\hline \multicolumn{4}{|l|}{ 2) Alternatif subsistensi } \\
\hline $\begin{array}{l}\text { Berjualan kecil-kecilan } \\
\text { Menggunakan barang bekas untuk }\end{array}$ & 26 & 61 & 13 \\
\hline kebutuhan rumah tangga & 83 & 13 & 4 \\
\hline Bekerja serabutan & 35 & 43 & 22 \\
\hline Melakukan migrasi untuk mencari & 4 & 13 & 83 \\
\hline
\end{tabular}

pekerjaan

\begin{tabular}{|c|c|c|c|}
\hline \multicolumn{4}{|l|}{$\begin{array}{l}\text { 3) Pengontrolan konsumsi dan } \\
\text { pengeluaran }\end{array}$} \\
\hline $\begin{array}{l}\text { Mengurangi pola makan, dari } 3 \text { kali } \\
\text { sehari menjadi }\end{array}$ & 65 & 22 & 13 \\
\hline 2 kali sehari & & & \\
\hline Membeli barang-barang murah & 76 & 21 & 3 \\
\hline Pembelian pakaian dalam setahun & 12 & 23 & 65 \\
\hline $\begin{array}{l}\text { Mengurangi pengeluaran untuk } \\
\text { kesehatan }\end{array}$ & 15 & 23 & 62 \\
\hline $\begin{array}{l}\text { Mengurangi pengeluaran untuk biaya } \\
\text { pendidikan }\end{array}$ & 13 & 22 & 65 \\
\hline
\end{tabular}

\section{Modal Sosial dan Strategi Bertahan Hidup}

Modal Sosial dalam penelitian ini lebih menekankan pada potensi kelompok dan polapola hubungan antar individu dalam suatu kelompok dan antar kelompok. Modal sosial lebih memperhatikan jaringan sosial, norma, dan kepercayaan antar sesama yang lahir dari anggota kelompok dan menjadi norma kelompok sehingga terjadi kerjasama yang saling menguntungkan, untuk mencapai tujuan bersama.

Tabel 10. Modal sosial : Menitipkan anak ke sanak saudara atau kerabat

\begin{tabular}{cccccc}
\hline No. & Menitipkan & \multicolumn{3}{c}{ Modal Sosial } & Jumlah \\
\cline { 3 - 5 } & anak ke & Kepercayaan & Norma & Jaringan & \\
sanak & & & & & \\
saudara & atau & & & & \\
kerabat & & & & & \\
& Baik & 315 & 252 & 252 & 819 \\
& Sedang & 930 & 744 & 496 & 2170 \\
\hline 1 & Kurang & 255 & 204 & 136 & 595 \\
\hline 3 & Jumlah & $\mathbf{1 5 0 0}$ & $\mathbf{1 2 0 0}$ & $\mathbf{8 8 4}$ & $\mathbf{3 5 8 4}$ \\
\hline
\end{tabular}

Tabel 10 menunjukkan modal sosial dalam strategi menitipkan anak ke sanak saudara atau kerabat adalah kuat, dengan jumlah 3584. Hal ini dikarenakan petani sering menitipkan anak kepada saudara, orang tua ataupun tetangga jika akan ke ladang/kebun, hal ini dikarenakan jam kerja di kebun/ladang memakan waktu yang cukup lama.

Tabel 11. Modal sosial : Strategi pinjaman uang

\begin{tabular}{cccccc}
\hline No. & $\begin{array}{c}\text { Strategi } \\
\text { pinjaman }\end{array}$ & \multicolumn{3}{c}{ Modal Sosial } & Jumlah \\
\cline { 3 - 5 } & uang & Kepercayaan & Norma & Jaringan & \\
\hline 1 & Baik & 1095 & 584 & 876 & 2555 \\
2 & Sedang & 255 & 204 & 204 & 663 \\
3 & Kurang & 150 & 120 & 80 & 350 \\
\hline & Jumlah & 1500 & 908 & 1160 & 3568 \\
\hline
\end{tabular}

Tabel 11 menunjukkan modal sosial dalam strategi pinjaman uang adalah kuat, dengan jumlah 3568. Strategi ini menjadi pilihan bagi petani miskin untuk menutupi kekurangan saat penghasilan tidak dalam kondisi yang baik. Selain itu strategi meminjam uang dilakukan petani miskin sebagai modal untuk bertanii. Misalkan untuk membeli bibit, pupuk dan mengolah lahan.

Tabel 12. Modal sosial : Mengikuti Arisan

\begin{tabular}{lccccc}
\hline \multirow{2}{*}{ No. } & $\begin{array}{c}\text { Mengikuti } \\
\text { arisan }\end{array}$ & \multicolumn{3}{c}{ Modal Sosial } & Jumlah \\
\cline { 3 - 5 } & Baik & 65 & 52 & 52 & 169 \\
\hline 1 & Kepercayaan & Norma & Jaringan & \\
2 & Sedang & 125 & 100 & 100 & 325 \\
3 & Kurang & 310 & 248 & 248 & 806 \\
\hline & Jumlah & $\mathbf{5 0 0}$ & $\mathbf{4 0 0}$ & $\mathbf{4 0 0}$ & $\mathbf{1 3 0 0}$ \\
\hline
\end{tabular}


Tabel 12 menunjukkan modal sosial dalam mengikuti arisan dalah lemah, dengan jumlah 1300. Mengikuti arisan belum menjadi pilihan bagi petani miskin sebagai strategi untuk bertahan hidup, dikarenakan pendapatan petani hanya cukup untuk memenuhi kebutuhan seharihari, pendidikan, serta biaya kesehatan.

Tabel 13. Modal sosial : Intensitas keluarga petani dalam mengikuti ibadah

\begin{tabular}{|c|c|c|c|c|c|}
\hline \multirow[t]{2}{*}{ No. } & \multirow[b]{2}{*}{$\begin{array}{l}\text { Intensitas } \\
\text { keluarga } \\
\text { petani } \\
\text { dalam } \\
\text { mengikuti } \\
\text { ibadah }\end{array}$} & \multicolumn{3}{|c|}{ Modal Sosial } & \multirow[t]{2}{*}{ Jumlah } \\
\hline & & Kepercayaan & Norma & Jaringan & \\
\hline 1 & Baik & 1170 & 936 & 624 & 2730 \\
\hline 2 & Sedang & 255 & 204 & 136 & 595 \\
\hline \multirow[t]{2}{*}{3} & Kurang & 75 & 60 & 40 & 175 \\
\hline & Jumlah & 1500 & 1200 & 800 & 3500 \\
\hline
\end{tabular}

Tabel 13 menunjukkan modal sosial dalam intensitas keluarga petani adalah kuat, dengan jumlah 3500. Mengikuti ibadah adalah bagian dalam kehidupan petani miskin. Bekerja sebagai petani tidak menjadi halangan bagi petani untuk menjalankan ibadah.

\begin{tabular}{lccccc} 
Tabel 14. Modal sosial : Mendapat bantuan pemerintah \\
\hline No. & $\begin{array}{c}\text { Mendapat } \\
\text { bantuan } \\
\text { pemerintah }\end{array}$ & \multicolumn{3}{c}{ Modal Sosial } & Jumlah \\
\cline { 3 - 5 } & Kepercayaan & Norma & Jaringan & \\
\hline 1 & Baik & 25 & 20 & 20 & 65 \\
2 & Sedang & 115 & 92 & 92 & 299 \\
3 & Kurang & 360 & 288 & 288 & 936 \\
\hline & Jumlah & 500 & 400 & 400 & 1300 \\
\hline
\end{tabular}

Tabel 14 maka modal sosial dalam mendapat bantuan pemerintah adalah lemah dengan jumlah 1300. Petani miskin mengungkapkan kurangnya bantuan pemerintah yang didapatkan petani. Penyaluran bantuan yang belum maksimal menjangkau seluruh petani miskin membuat petani kekurangan modal dan memilih untuk melakukan pinjaman.

Tabel 15. Modal sosial : Berjualan kecil-kecilan

\begin{tabular}{|c|c|c|c|c|c|}
\hline \multirow[t]{2}{*}{ No. } & \multirow{2}{*}{$\begin{array}{c}\text { Berjualan } \\
\text { kecil- } \\
\text { kecilan }\end{array}$} & \multicolumn{3}{|c|}{ Modal Sosial } & \multirow[t]{2}{*}{ Jumlah } \\
\hline & & Kepercayaan & Norma & Jaringan & \\
\hline 1 & Baik & 390 & 208 & 208 & 806 \\
\hline 2 & Sedang & 915 & 488 & 732 & 2135 \\
\hline \multirow[t]{2}{*}{3} & Kurang & 195 & 104 & 156 & 455 \\
\hline & Jumlah & 1500 & 800 & 1096 & 3396 \\
\hline
\end{tabular}

Tabel 15 menunjukkan modal sosial dalam berjualan kecil-kecilan adalah kuat dengan jumlah 3396. Selain melakukan usaha tani, petani memilih alternatif berjualan kecilkecilan untuk memenuhi kebutuhan hidup sehari-hari dan sebagai strategi untuk bertahan hidup. Usaha kecil-kecilan yang dilakukan petani adalah membuka warung dan berjualan kue.

Tabel 16. Modal sosial : Menggunakan barang bekas untuk kebutuhan rumah tangga

\begin{tabular}{|c|c|c|c|c|c|}
\hline \multirow[t]{2}{*}{ No. } & \multirow{2}{*}{$\begin{array}{c}\text { Menggunakan } \\
\text { barang bekas } \\
\text { untuk } \\
\text { kebutuhan } \\
\text { rumah tangga }\end{array}$} & \multicolumn{3}{|c|}{ Modal Sosial } & \multirow[t]{2}{*}{ Jumlah } \\
\hline & & Kepercayaan & Norma & Jaringan & \\
\hline 1 & Baik & 1245 & 996 & 996 & 3237 \\
\hline 2 & Sedang & 195 & 156 & 104 & 455 \\
\hline \multirow[t]{2}{*}{3} & Kurang & 60 & 48 & 32 & 140 \\
\hline & Jumlah & 1500 & 1200 & 1132 & 3832 \\
\hline
\end{tabular}

Tabel 16 menunjukkan modal sosial dalam menggunakan barang bekas untuk kebutuhan rumah tangga adalah kuat dengan jumlah 3832. Petani menggunakan barang yang rusak untuk dijadikan perabotan dalam rumah. Barang bekas di dapatkan petani dengan cara membeli, memungut dari tempat pembuangan barang bekas, ataupun barang bekas pemberian orang lain.

Tabel 17. Modal sosial : Bekerja serabutan

\begin{tabular}{lccccc}
\hline No. & Bekerja & \multicolumn{3}{c}{ Modal Sosial } & Jumlah \\
\cline { 3 - 5 } & serabutan & Kepercayaan & Norma & Jaringan & \\
\hline 1 & Baik & 350 & 140 & 280 & 770 \\
2 & Sedang & 430 & 172 & 344 & 946 \\
3 & Kurang & 220 & 88 & 176 & 484 \\
\hline & Jumlah & 1000 & 400 & 800 & 2200
\end{tabular}

Tabel 17 menunjukkan modal sosial dalam bekerja serabutan adalah cukup dengan jumlah 2200. Petani memilih alternatif bekerja serabutan untuk memenuhi kebutuhan sehari-hari yang merupakan strategi untuk dapat bertahan hidup. Selain bertani pekerjaan serabutan yang dilakukan oleh petani yaitu bekerja sebagai buruh dan tukang.

Tabel 18. Modal sosial : Melakukan migrasi untuk mencari pekerjaan

\begin{tabular}{cccccc}
\hline No. & $\begin{array}{c}\text { Melakukan } \\
\text { migrasi } \\
\text { untuk } \\
\text { mencari }\end{array}$ & \multicolumn{3}{c}{ Modal Sosial } & Jumlah \\
\cline { 3 - 5 } & & & & & \\
pekerjaan & & & & & \\
\hline 1 & Baik & 20 & 16 & 16 & 52 \\
2 & Sedang & 65 & 52 & 52 & 169 \\
3 & Kurang & 415 & 332 & 332 & 1079 \\
\hline & Jumlah & $\mathbf{5 0 0}$ & $\mathbf{4 0 0}$ & $\mathbf{4 0 0}$ & $\mathbf{1 3 0 0}$ \\
\hline
\end{tabular}

Tabel 18 maka modal sosial dalam melakukan migrasi untuk mencari pekerjaan adalah lemah dengan jumlah 1300 . Hanya sedikit petani yang memilih alternatif ini. Hanya ada 
beberapa anggota keluarga petani yang melakukan migrasi untuk mencari pekerjaan. Petani lebih memilih bekerja serabutan sekaligus bertani dibandingkan harus bermigrasi pekerjaan.

Tabel 19. Modal sosial : Mengurangi pola makan, dari 3 kali sehari
menjadi 2 kali sehari

Tabel 19 maka modal sosial dalam mengurangi pola makan, dari 3 kali sehari menjadi 2 kali sehari adalah kuat dengan jumlah 3377. Petani memilih untuk mengurangi pola makan untuk menghemat biaya hidup. Jika pendapatan dari hasil bertani ataupun dari pekerjaan serabutan mencukupi, petani menambah pola makan menjadi tiga kali sehari.

\begin{tabular}{lccccc}
\multicolumn{6}{c}{ Tabel 20. Modal sosial : Membeli barang-barang murah } \\
\hline No. & $\begin{array}{c}\text { Membeli } \\
\text { barang- } \\
\text { barang }\end{array}$ & \multicolumn{3}{c}{ Modal Sosial } & Jumlah \\
\cline { 3 - 5 } & Kepercayaan & Norma & Jaringan & \\
\cline { 3 - 5 } & murah & & & & \\
\hline 1 & Baik & 1140 & 912 & 608 & 2660 \\
2 & Sedang & 315 & 252 & 104 & 671 \\
3 & Kurang & 45 & 36 & 24 & 105 \\
\hline & Jumlah & $\mathbf{1 5 0 0}$ & $\mathbf{1 2 0 0}$ & $\mathbf{7 3 6}$ & $\mathbf{3 4 3 6}$ \\
\hline
\end{tabular}

Tabel 20 menunjukkan modal sosial dalam membeli barang-barang murah adalah kuat dengan jumlah 3436. Petani memilih untuk membeli barang murah untuk menyesuaikan dengan penghasilan yang didapat. Selain penggunaan barang bekas, membeli barang murah menjadi pilihan utama bagi petani.

\begin{tabular}{|c|c|c|c|c|c|}
\hline \multirow[t]{2}{*}{ No. } & \multirow{2}{*}{$\begin{array}{c}\text { Pembelian } \\
\text { pakaian } \\
\text { dalam } \\
\text { setahun }\end{array}$} & \multicolumn{3}{|c|}{ Modal Sosial } & \multirow[t]{2}{*}{ Jumlah } \\
\hline & & Kepercayaan & Norma & Jaringan & \\
\hline 1 & Baik & 60 & 48 & 60 & 168 \\
\hline 2 & Sedang & 115 & 184 & 115 & 414 \\
\hline \multirow[t]{2}{*}{3} & Kurang & 325 & 520 & 325 & 1170 \\
\hline & Jumlah & 500 & 752 & 500 & 1752 \\
\hline
\end{tabular}

Tabel 21 menunjukkan modal sosial dalam Pembelian pakaian dalam setahun adalah cukup dengan jumlah 1752. Untuk pembelian pakaian, biasanya dilakukan petani pada hari raya besar keagamaan. Jika penghasilan tidak memungkinkan, maka dalam setahun tidak ada pembelian pakaian yang dilakukan.

\begin{tabular}{lccccc}
\multicolumn{2}{l}{ Tabel 22. Modal sosial : Mengurangi pengeluaran untuk kesehatan } \\
\hline No. & \begin{tabular}{c} 
Mengurangi \\
pengeluaran \\
untuk \\
\cline { 3 - 5 }
\end{tabular} & \multicolumn{3}{c}{ Modal Sosial } & Jumlah \\
kesehatan & Kepercayaan & Norma & Jaringan & \\
\hline 1 & Baik & 150 & 120 & 60 & 330 \\
2 & Sedang & 230 & 184 & 92 & 506 \\
3 & Kurang & 620 & 496 & 496 & 1612 \\
\hline & Jumlah & $\mathbf{1 0 0 0}$ & $\mathbf{8 0 0}$ & $\mathbf{6 4 8}$ & $\mathbf{2 4 4 8}$ \\
\hline
\end{tabular}

Tabel 22 menunjukkan modal sosial dalam mengurangi pengeluaran untuk kesehatan adalah cukup dengan jumlah 2448. Pengurangan pengeluaran kesehatan dilakukan untuk mencukupi kehidupan sehari-hari dan biaya pendidikan. Biaya kesehatan belum menjadi prioritas utama bagi petani miskin.

\begin{tabular}{|c|c|c|c|c|c|}
\hline \multirow[t]{2}{*}{ No. } & \multirow{2}{*}{$\begin{array}{l}\text { Mengurangi } \\
\text { pengeluaran } \\
\text { untuk biaya } \\
\text { pendidikan }\end{array}$} & \multicolumn{3}{|c|}{ Modal Sosial } & \multirow{2}{*}{ Jumlah } \\
\hline & & Kepercayaan & Norma & Jaringan & \\
\hline 1 & Baik & 130 & 104 & 52 & 286 \\
\hline 2 & Sedang & 220 & 176 & 176 & 572 \\
\hline \multirow[t]{2}{*}{3} & Kurang & 650 & 780 & 260 & 1690 \\
\hline & Jumlah & 1000 & 1060 & 488 & 2548 \\
\hline
\end{tabular}

Tabel 23 menunjukkan modal sosial dalam mengurangi pengeluaran untuk biaya pendidikan adalah cukup dengan jumlah 2548 . Pengurangan pengeluaran dibidang pendidikan dilakukan karena keterbatasan biaya untuk melanjutkan ke jenjang pendidikan yang lebih tinggi. Pada umumnya petani dan keluarga hanya mencapai jenjang SMA.

\section{KESIMPULAN DAN SARAN}

\section{Kesimpulan}

Hasil penelitian menunjukan bahwa Modal sosial yang kuat, maka akan baik strategi bertahan hidup dari petani miskin sebaliknya Modal sosial lemah, maka strategi bertahan hidup petani miskin, menjadi kurang. Strategi Bertahan Hidup pada Relasi atau jaringan sosial kuat dicirikan pada menitip anak pada saudara, strategi peminjaman uang dan intensitas dalam mengikutin ibadah, dan lemah pada mengikuti arisan dan mendapat bantuan pemerintah.

Strategi bertahan hidup pada alternatif subsistens kuat dicirikan pada berjualan kecilkecilan dan mengunakan barang bekasuntuk kebutuhan rumah tangga, cukup dicirikan pada bekerja serabutan dan lemah dicirikan pada melakukan migrasi untuk mencari pekerjaan. 
Strategi bertahan hidup pada pengontrolan konsumsi dan pengeluaran kuat dicirikan pada Mengurangi pola makan, dari 3 kali sehari menjadi 2 kali sehari dan Membeli barang-barang murah, cukup dicirikan pada pembelian pakaian dalam setahun, mengurangi pengeluaran untuk kesehatan dan mengurangi pembiayaan untuk pendidikan.

\section{Saran}

Petani harus menekankan pada potensi kelompok dan pola-pola hubungan antar individu dalam suatu kelompok dan antar kelompok. Selain itu petani harus memperhatikan jaringan sosial, norma, dan kepercayaan antar sesama anggota kelompok serta menjadi norma kelompok sehingga terjadi kerjasama yang saling menguntungkan, untuk mencapai tujuan bersama.

\section{DAFTAR PUSTAKA}

Alfurkon Setiawan. 2014. Sekertariat kabinet Republik Indonesia. https://setkab.go.id/posisi- pertanianyang-tetap-strategis-masa-kini-danmasa-depan/. Diakses tpada tanggal 10 Oktober 2019.

[BPS] Badan Pusat Statistik Kabupaten Minahasa. 2019. Kabupaten Minahasa Dalam Angka 2019. Minahasa: BPS Kabupaten Minahasa.

[BPS] Badan Pusat Statistik Sulawesi Utara. 2019. Sulawesi Utara Dalam Angka 2019. Manado: BPS Sulawesi Utara.

Hasbullah, Jousairi. 2006. Sosial Capital: Menuju Keunggulan Budaya Manusia Indonesia. MR-United Press. Jakarta.

Ira Araini sam, 2006. Pemberdayaan anak jalanan melalui rumah singgah, Makassar, Skiripsi Unhas.
Mulyono. S. 2006. Statistika Untuk Ekonomi. Fakultas Ekonomi Universitas Indonesia. Depok.

Ngangi, Charles. 2016. Modal Sosial. Unsrat Press, Manado.

Ngangi, Charles. 2013. Modal Sosial Masyarakat Sulawesi Utara. Jurnal Lasallian Volume 10 Nomor 2. 2 September 2013 Unika De La Salle. H. 1-5.

Ngangi, Charles. 2013. Faktor Modal Sosial dalam Program Pengentasan Kemiskinan untuk Meningkatkan Nilai Tukar Rumah Tangga Petani di Kabupaten Kepulauan Talaud. Unsrat Manado.

Ngangi Charles. L.R Rengkung; M.L.G Tarore. 2014. Modal Sosial dan Strategi Partisipasi Masyarakat dalam Penanggulangan Kemiskinan di Kabupaten Minahasa Tenggara. Lembaga Penelitian dan Partisipasi Masyarakat Unsrat. Manado.

Pusat Data dan Sistem Informasi Pertanian. 2018. Statistik Ketenagakerjaan Sektor Pertanian. Sekertariat jendral kementerian pertanian.

Suharto Edi. 2009. Kemiskinan dan Perlindungan Sosial di Indonesia: Menggagas Model Jaminan Sosial Universitas Bidang Kesehatan. Alfabeta. Bandung.

Suharto, Edi. 2009. Membangun Masyarakat Memberdayakan Masyarakat. (Bandung: PT Refika Aditama).

Sugihardjo, dkk. 2012. Strategi Bertahan dan Strategi Adaptasi Petani Samin Terhadap Dunia Luar. SEPA Vol. 8 No. 2. Universitas Sebelas Maret. Surakarta. 